\title{
Smartphone Addiction in Mexican Engineering Students
}

\author{
https://doi.org/10.3991/ijim.v15i22.23357
}

\author{
Arturo García-Santillán ${ }^{1}$, Elena Moreno-García ${ }^{2(\mathbb{})}$, Valerie Martínez-Rodríguez \\ ${ }^{1}$ Universidad Cristóbal Colón, Veracruz, México \\ ${ }^{2}$ Instituto Tecnológico Superior de Misantla, Veracruz, México \\ emorenog@itsm.edu.mx
}

\begin{abstract}
Students academic performance could be affected by excessive use of the smartphone. This study focuses on analyzing the level of cell phone addiction in engineering university students. It also seeks to determine if there is a difference by gender in this behavior. 306 engineering students from a Technological Institute in Veracruz, Mexico participated in the study. The instrument used to obtain data was SAS-SV (Smartphone addiction scale-short version). In order to identify the set of indicators with the highest factor loadings, an exploratory factor analysis was carried out with extraction of components and orthogonal rotation with the Varimax method. To identify if there is a difference by gender, the $t$ test is used to contrast the hypothesis about two independent population means. The findings demonstrated the extraction of two components and no difference was found between the groups of male and female students.
\end{abstract}

Keywords—-smartphone, engineering students, addiction, gender, mexico

\section{Introduction}

Smartphone addiction is a phenomenon that has drawn the attention of researchers. It has been the subject of various empirical studies [1-11]. The growth that the telephone communications sector has shown has led to the diverse range of smart devices called smartphone or mobile phones.

However, the debate in the scientific discourse is about the possible addiction that the smartphone has generated in users, which leads to the following questions: does the smartphone really generate addiction? And in a very particular way, does the mobile phone generate addiction in college students? This research seeks to identify the levels of addiction in students.

The literature provides evidence that there is addiction to the smartphone in various populations studied. Also, that addiction has occurred at levels that have differed by gender, as demonstrated by the study by [2] and [10]. Therefore, this study also seeks to generate evidence on the difference between men and women in relation to a possible addiction to the mobile phone. 


\section{$2 \quad$ Literature review}

According to [1], smartphone addiction is understood to be the problematic or excessive, as well as obsessive, use of any mobile phone. That frequent use of the smartphone cannot be defined as a pathological behavior, unless it is accompanied by symptoms that are characterized by addictive disorders [12].

The research carried out by [2], points out that the addictive levels of the smartphone were higher in women and with respect to its excessive use, it was more than 16 hours compared to those who only used it 4 hours.

On the other hand, [1] designed the Propensity Scale to Addiction to Smartphones (SAPS), which was applied to 795 students in Korea. In this sample, $44.7 \%$ were high school students, 461 men and 324 women. The results showed that the excessive use of digital media devices can have negative consequences in social, physical and psychological aspects in the lives of adolescents, in addition to generating criminal behaviors.

The short version of the Smartphone Addiction Scale (SAS-SV) was adapted by [13] to Spanish and French and it was applied online to 281 and 144 volunteers over 18 years of age from Spain and Belgium respectively. The results show the excessive use of the smartphone of $12.5 \%$ for the Spanish and $21.5 \%$ for the Belgians. No differences by gender were found. It was discovered that the Spanish have more smartphones and triple the time of use compared to the Belgians, however the Belgians use the smartphone addictively compared to the Spanish, that is, the Belgians presented abstinence, loss of control and tolerance, while the Spanish presented tolerance, then loss of control and finally abstinence.

In South Korea, a population of 448 university students was study by [3] applying the Smartphone Addiction Scale. The results obtained show the risk factors for smartphone addiction in women, such as the consumption of the internet, alcohol and suffering from anxiety symptoms. It is negatively associated with depression and temperance (implies self-regulation). On the other hand, the risk factors in men were associated with internet and smartphone addiction including anxiety symptoms and the need to obtain knowledge. In a negative way, it was associated with strength-courage (it has to do with vitality and courage). The differences may be due to the high availability and use that is given to the smartphone as a tool to maintain interpersonal relationships.

The purpose of the study by [14] was to investigate the impact of self-regulation (self-control of the individual) and compulsiveness (discomfort, anguish, anxiety, tension) in smartphone addiction. 157 Thai university students were surveyed, of which $57.3 \%$ were men. The conceptual model explains $60.4 \%$ of the variance in smartphone addiction and compulsiveness is only found as a determining factor in smartphone addiction.

After applying the Smartphone Addiction Inventory (SPAI) to 485 Italian university students, [15] identified that the negative consequences and the experience of psychological feelings of not being able to use the smartphone are characteristics of compulsive behavior. This behavior can affect interpersonal relationships depending on the amount of time spent on the smartphone.

In Turkey, [5] carried out the online application of a questionnaire to analyze the roles of smartphone use, self-regulation, general self-efficacy and cyberspace in smartphone addiction. 598 university students responded to the survey. The results showed that those students with self-regulation skills showed less addictive behavior on the phone. 
In addition, both the duration granted to the smartphone and cyber-loafing (cyber laziness, that is, waste of time during school hours or work day checking social networks, personal messaging, among others) will affect the addiction to the smartphone.

Research by [6] refers that smartphone addiction was highly correlated with internet addiction, due to the easy access and availability of information at the time it is required. This increases addiction by quickly meeting their need.

At the University of Notre Dame-Louaize in Lebanon, [16] showed that both, men and women, were susceptible to being addicted to the smartphone, with a participation of 293 university students using the short scale of addiction to the smartphone (SAS-SV). It was also identified that those students with a high risk of smartphone addiction were less likely to achieve higher cumulative grade point average or distinction. Another finding in this research is that those students who spend more time on their smartphone reduce their participation in group activities and the reading time related to academic tasks. In addition, it hinders maintaining an adequate concentration in their studies.

In Turkey 785 students were surveyed in Trakya University, 91.7\% had a smartphone. The highest level of addiction in the use of the smartphone was in students aged 20 years or less, the highest scores revealed that addiction affects social life, verbal communication and leads to academic difficulties [4].

The research conducted by [17] surveyed 308 North American participants of Amazon's Mechanical Turk, people who spoke English and were at least 18 years old. Its objective was to investigate two types of smartphone use, the use of processes that involve non-social functions such as the consumption of news, entertainment, relaxation and social use related to social networks and messaging. They found that the latter was strongly associated with symptoms of anxiety and depression. On the other hand, the use of a non-social process was linked between the severity of anxiety symptoms and smartphone addiction.

At the University of Bangladesh, [7] collected 247 questionnaires from business students, of which $54.25 \%$ were men and $45.75 \%$ were women between the ages of 18 and 27. 35 variables identified in smartphone addiction were categorized into five factors that were found from the rotated factor matrix analysis:

(1) Disturbance of daily life: it is the most important factor regarding smartphone addiction obtaining the highest value. It indicates that the use of the smartphone is not only a concern of academic performance but also disturbs physical strength, family relationships, attendance on time to classes and planned work. It includes variables such as "my family relationship has decreased", "I feel pain in my wrists", "lack of planning makes it difficult for me to concentrate", "I feel tired or I am not able to sleep enough".

(2) Positive anticipation: there are variables such as "feeling pleasant or excited", "life would be empty without my smartphone", "I can get rid of stress".

(3) Withdrawal: this section involves abstinence, which includes variables such as "I feel impatient and restless", "I take my smartphone to the bathroom", "I can't stop using my smartphone", "I feel anxious because I can't receive important calls", among others.

(4) Cyber friendship: it is made up of variables such as "the relationship I have with my smartphone friends is more intimate", "I constantly check my smartphone", "I check my social networks". 
(5) Greater impatience or tolerance: the main characteristic of this section is that the increase in the use of the smartphone generates impatience among students to carry out their usual activities, since they consume valuable time. It includes variables such as: I feel the need to use my smartphone; I have always thought that I should shorten the time I use the smartphone; I think while I rest, just give me a few more minutes to continue using it.

This study showed that the regular academic performance of students will be hampered by excessive use of the smartphone, if they use it more than they plan. It is an obstacle to their family relationship, their need to use it is so great that they take it to the bathroom. Even at school at recess they use it when it is supposed to be time to relax or use it late at night, which can cause tension, pain in the wrists or neck, impatience and poor school performance. In addition to the above, research suggests that they should reduce excessive use of the smartphone to be able to carry out their daily activities without difficulty [7].

In Istanbul, Turkey, 367 university students were surveyed with the aim of determining the relationship between smartphone addiction, social phobia and loneliness. $95 \%$ of the students who participated had an account on any social media site. The results show that social phobia and smartphone addiction are associated, due to the fact that younger people use it excessively to access their social networks, compared to those who only used it to surf the internet or make phone calls [8].

Another aspect that [8] highlight in their research is that people with social anxiety preferred to use their smartphone to send text messages to avoid face-to-face communication, while people with feelings of loneliness preferred to surf the internet or play games. This feeling of loneliness was correlated with a high risk of smartphone addiction in most of the study participants.

More than half of the university students surveyed report that they use the smartphone during classes or meetings, also that they use it at night in their bed, which showed risky behavior in their sleep activity. Furthermore, $65 \%$ of the students mentioned that they use it while walking and $12 \%$ reported that they use it while driving [8].

There were 324 nursing college students in Seoul, Korea, surveyed in the research conducted by [9]. The level of smartphone addiction identified in this research showed a lower rank than other university students, which means that they exercise self-control to achieve long-term academic results. It also shows that cyberspace-oriented relationships and social support are positively correlated with university nursing students, which implies that the smartphone strengthens family ties, facilitates the proximity of the people they call and improves their interpersonal networks through social networks. Its use is also associated with academic consultations of websites to obtain specialized knowledge, so there are likely to be benefits related to the motivation of nursing university students.

In a health school of the University of Turkey, [18] applied 214 questionnaires, of which 172 were women and 42 men. Their findings are consistent with those obtained in other investigations [2-6, 8-9], showing low levels for smartphone addiction. They also identified that in case of increasing the use of the smartphone, it could create an addiction and decrease the communication skills of the nursing university students.

Another study, with 174 Saudi university students, 99 men and 75 women between the ages of 19 and 23, shows that women were the ones who spent more time using the smartphone on a daily basis. It also discovered that for learning purposes, its use is 
reduced. The conclusions of the [10] research indicates that Saudi students are addicted to the smartphone because they do not turn it off to sleep, they become stressed or upset if they are asked to put it aside for a moment or for a certain time and they become anxious about the battery level they have. $80 \%$ of their addiction is not due to academic reasons, it was identified that they constantly check their smartphone. The applications they use the most are WhatsApp, Twitter and Sports. In addition, 81\% of respondents use it to navigate their social networks.

The study carried out by [11] selected 68 students from four different schools to explore the combined effects of self-regulated learning and academic procrastination on smartphone addiction. Their results show that those students who use the smartphone excessively can hardly achieve high academic performance and frequently delay the completion of assigned tasks. It concludes that training students in strategies to self-regulate learning effectively will be fundamental and beneficial for them.

Because the excessive use of smartphone could derivate in student's addictive behavior and this become into poor academic performance, the following questions arise: Are Mexican engineering students addict to their smartphones? What is the level of their addiction? Does smartphone use differ by gender? Next, the method to be developed for the empirical study is defined, which seeks to find an answer to the question and the purpose that has been established for this work.

\section{Method}

This study is of a non-experimental design, which seeks to answer the question from the hypothetical deductive, cross-sectioned method. Its scope is descriptive, exploratory, correlational, explanatory and mean difference.

Sampling inclusion criteria was to be student enrolled in the 2019-2020 school year in any grade and any program of the Institute of Technology in Veracruz, Mexico. At all times, students were informed of the scope and reason for the study and their participation was voluntarily and anonymous. 306 students accepted to participate in the study.

The study was carried out at the invitation by one of the directors of the institution who provided the means to carry out the survey electronically.

The instrument used to obtain data in the field application was the SAS-SV (Smartphone addiction scale-short version) designed by [19] (see Appendix 1). This scale has been validated in other studies from its construction and application in South Korea, and was originally published in English by [19]. The composition of the scale are indicators of the profile (age, semester and gender) and ten items with Likert-type response options ranging from: rarely 1 to always 5. The minimum score is 10 and the maximum 50 , being the lowest level and higher addiction in the extremes. If the score is in the levels of 30 to 40 it is considered necessary to pay attention to the behavior. The psychometric properties of the scale have been referenced in the work of [13] with a Cronbach's alpha of 0.91 , which is very acceptable in the theoretical terms suggested by [20].

The SPSS v23 software was used to analyze data. By means of the exploratory factor analysis in the first place it is verified that the data matrix is not an identity matrix and that the value of the determinant is as close to zero. In addition, the measure of sample adequacy per variable (MSA) and the value of the Bartlett test of sphericity with Kaiser-Meyer-Olkin (KMO) test and Chi2 with $n=g l$ are used to justify the use of the 
factorial technique and extract the factors that explain the highest percentage possible variance of the study phenomenon. The decision criterion in this first step is to reject $\mathrm{H} 0$ if the calculated Chi2 is greater than the Chi2 of the tables, otherwise it is not rejected.

It is important to note that for the extraction of the components, the orthogonal rotation is carried out with the Varimax method to identify the set of indicators with the highest factorial loads of the structure that underlies this phenomenon [21] and that it seeks to empirically test [22]. Similarly, it is considered important to calculate the polychoric correlation matrix based on the suggestion of [23] and [24], since the instrument is of Likert-type design. Finally, to identify if there is a significant difference by gender, the $t$ test for independent samples is used in order to test the hypothesis about two independent population means.

\section{Results}

First, the scale is validated with Cronbach's alpha to determine its reliability and validity. The result obtained from the 13 items of the instrument is $\alpha=0.733$ (includes gender, age and semester of the respondent) and with the 10 items of the scale it is $\alpha=0.860$ in both cases the internal consistency of the scale presents acceptable values according to theoretical criteria [20]. Table 1 shows the main frequencies of the participants' profile and the descriptive mean and standard deviation.

Table 1. Descriptives

\begin{tabular}{|c|c|c|c|c|c|c|}
\hline Variable & \multicolumn{2}{|c|}{ Frequencies } & $\%$ & $\sum$ & $\mu$ & St. Desv. \\
\hline \multirow{2}{*}{ Gender } & Male & 155 & $50.65 \%$ & $50.65 \%$ & \multirow{2}{*}{1.4935} & \multirow{2}{*}{0.50078} \\
\hline & Female & 151 & $49.35 \%$ & $100.00 \%$ & & \\
\hline \multirow[t]{4}{*}{ Age } & $17-19$ & 183 & $59.80 \%$ & $59.80 \%$ & \multirow{4}{*}{1.89222} & \multirow{4}{*}{1.06731} \\
\hline & $20-22$ & 68 & $22.22 \%$ & $82.03 \%$ & & \\
\hline & $23-25$ & 41 & $13.40 \%$ & $95.42 \%$ & & \\
\hline & $26-30$ & 14 & $4.58 \%$ & $100.00 \%$ & & \\
\hline \multirow[t]{9}{*}{ Semester } & 1 & 84 & $27.45 \%$ & $27.45 \%$ & \multirow{9}{*}{3.9673} & \multirow{9}{*}{2.54898} \\
\hline & 2 & 34 & $11.11 \%$ & $38.56 \%$ & & \\
\hline & 3 & 23 & $7.52 \%$ & $46.08 \%$ & & \\
\hline & 4 & 11 & $3.59 \%$ & $49.67 \%$ & & \\
\hline & 5 & 88 & $28.76 \%$ & $78.43 \%$ & & \\
\hline & 6 & 9 & $2.94 \%$ & $81.37 \%$ & & \\
\hline & 7 & 20 & $6.54 \%$ & $87.91 \%$ & & \\
\hline & 8 & 18 & $5.88 \%$ & $93.79 \%$ & & \\
\hline & 9 & 19 & $6.21 \%$ & $100.00 \%$ & & \\
\hline
\end{tabular}

Source: own.

As can be seen in Table 1, participation was balanced in terms of gender. Practically $50 \%$ in both cases, with a slight difference of only 4 cases. As for age, a greater number of cases is observed in the age range of 17 to 19 years, which is the approximate average age of freshmen. $27.45 \%$ corresponds to the first semester and $28.76 \%$ to the fifth semester. 
To verify that the data matrix does not constitute an identity matrix, Table 2 now shows the correlation matrix, the determinant and the value of the sample adequacy measure per variable (MSA).

Table 2. Correlation matrix and MSA

\begin{tabular}{|l|c|c|c|c|c|c|c|c|c|c|c|}
\hline Correlation & $\begin{array}{c}\text { Item } \\
\mathbf{1}\end{array}$ & $\mathbf{2}$ & $\mathbf{3}$ & $\mathbf{4}$ & $\mathbf{5}$ & $\mathbf{6}$ & $\mathbf{7}$ & $\begin{array}{c}\text { Item } \\
\mathbf{8}\end{array}$ & $\begin{array}{c}\text { Item } \\
\mathbf{9}\end{array}$ & $\begin{array}{c}\text { Item } \\
\mathbf{1 0}\end{array}$ & $\begin{array}{c}\text { Item } \\
\text { Item }\end{array}$ \\
\hline Item1 & 1.00 & .284 & .322 & .308 & .286 & .322 & .242 & .212 & .391 & .288 & $.890^{\mathrm{a}}$ \\
\hline Item2 & & 1.00 & .183 & .310 & .249 & .182 & .209 & .231 & .243 & .196 & $.836^{\mathrm{a}}$ \\
\hline Item3 & & & 1.00 & .573 & .343 & .637 & .388 & .425 & .451 & .388 & $.840^{\mathrm{a}}$ \\
\hline Item4 & & & & 1.00 & .423 & .498 & .383 & .348 & .377 & .391 & $.857^{\mathrm{a}}$ \\
\hline Item5 & & & & & 1.000 & .384 & .273 & .264 & .370 & .279 & $.915^{\mathrm{a}}$ \\
\hline Item6 & & & & & & 1.00 & .483 & .489 & .514 & .409 & $.896^{\mathrm{a}}$ \\
\hline Item7 & & & & & & & 1.00 & .853 & .545 & .455 & $.746^{\mathrm{a}}$ \\
\hline Item8 & & & & & & & & 1.00 & .517 & .452 & $.745^{\mathrm{a}}$ \\
\hline Item9 & & & & & & & & & 1.00 & .463 & $.921^{\mathrm{a}}$ \\
\hline Item10 & & & & & & & & & & 1.00 & $.951^{\mathrm{a}}$ \\
\hline
\end{tabular}

Note: ${ }^{\text {a Determinant }}=.015$.

Source: own.

As Table 2 shows, the significance of the correlation matrix is acceptable, and it is verified that it is not an identity matrix. The determinant close to zero is proof of acceptable correlations and the factorization can be developed. Table 3 shows the analysis of the rotated factors, each one comprising 5 indicators.

Table 3. Rotated components matrix

\begin{tabular}{|c|c|c|}
\hline \multicolumn{3}{|c|}{ Rotated Component Matrix ${ }^{a}$} \\
\hline \multirow{2}{*}{ Indicators } & \multicolumn{2}{|c|}{ Component } \\
\hline & 1 & 2 \\
\hline Item8 & 0.908 & \\
\hline Item7 & 0.906 & \\
\hline Item9 & 0.632 & \\
\hline Item10 & 0.587 & \\
\hline Item6 & 0.582 & \\
\hline Item4 & & 0.675 \\
\hline Item5 & & 0.655 \\
\hline Item1 & & 0.654 \\
\hline Item2 & & 0.581 \\
\hline Item3 & & 0.565 \\
\hline Self-value & 4.471 & 1.155 \\
\hline$\%$ de variance & $44.71 \%$ & $11.55 \%$ \\
\hline
\end{tabular}

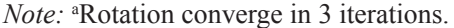

Source: own. 
As we can see in Table 3, Component 1 is made up of the indicators item8, item 7, item 9 , item 10 and item 6 with an eigenvalue of 4.471 which represents $44.71 \%$ of the assimilable variance, and component 2 is made up of the items item 4 , item 5 , item 1 , item 2, item 3 with an eigenvalue of 1.155 that represents $11.55 \%$ of the variance. Hence, the total variance that explains the addiction to the smartphone can be explained in $56.265 \%$.

For component 1, called the Dependency Component, we observe that the indicators that make it up are oriented towards the dependence of the subjects towards the smartphone, this argument is presented considering the following: they constantly checking the smartphone in order to not to miss the conversations in Twitter or Facebook among other people.

In the same way, they report that never stop using the smartphone, even when the individual's daily life is already greatly affected by it. In addition, they use the smartphone for longer than the individual had planned, as well, when the people around the subject tell him that he uses the smartphone too much and finally, having the smartphone in the individual's mind even when he does not are using, then we might think that there is a dependency between the subject and the smartphone. These factor loadings that provide a significant eigenvalue contribute to the variance of the phenomenon studied in $44.71 \%$.

In relation to the second component called Frustration, we observe the existence of some situations that generate a feeling of frustration in the individual, since he won't be able to stand not having a smartphone. Feeling impatient and fretful when I am not holding my smartphone. Missing planned work due to smartphone use. Having a hard time concentrating in class, while doing assignments, or while working due to smartphone use. Feeling pain in the wrists or at the back of the neck while using a smartphone. These aspects that make up the second component explain $11.55 \%$ of the variance and also contribute to the explanation of addiction to the smart phone in the users who were the object of the study.

About of the levels of addiction, as well frequency, percentages and sample accumulation, in Table 4 show the results.

Table 4. Level of addiction and prevalence percentage

\begin{tabular}{|l|c|c|c|}
\hline \multicolumn{1}{|c|}{ Level of Addiction } & Frequency & Percentage & Cumulative Percentage \\
\hline Low & 125 & 40.8 & 40.8 \\
\hline Medium & 117 & 38.2 & 79.1 \\
\hline High & 64 & 20.9 & 100.0 \\
\hline Total & 306 & 100.0 & \\
\hline
\end{tabular}

Source: own.

One of the objectives of the study is to determine if there is a difference in levels of mobile phone addiction in terms of gender. For this, the hypothesis test is carried out using the ANOVA of a factor to obtain the values of $\mathrm{F}$ and the Levene statistic with $\mathrm{n}$ gl1 $\mathrm{m}$ and $\mathrm{gl} 2$ and significance 0.05 (Tables 5 and 6). 
Table 5. ANOVA test

\begin{tabular}{|l|c|c|c|c|}
\hline Variable & Inter-Groups $(\mathbf{d f}=\mathbf{1})$ & Intra-Groups $(\mathbf{d f}=\mathbf{3 0 4})$ & $\mathbf{F}$ & Sig. \\
\hline $\mathrm{X} 1$ & 1.39 & 1.134 & 1.225 & 0.269 \\
\hline $\mathrm{X} 2$ & 1.738 & 1.11 & 1.566 & 0.212 \\
\hline $\mathrm{X} 3$ & 2.766 & 1.434 & 1.928 & 0.166 \\
\hline $\mathrm{X} 4$ & 0.46 & 1.164 & 0.395 & 0.530 \\
\hline $\mathrm{X} 5$ & 2.067 & 1.101 & 1.878 & 0.172 \\
\hline $\mathrm{X} 6$ & 0.041 & 1.389 & 0.034 & 0.863 \\
\hline $\mathrm{X} 7$ & 1.519 & 1.64 & 0.926 & 0.337 \\
\hline $\mathrm{X} 8$ & 0.847 & 1.732 & 0.489 & 0.485 \\
\hline $\mathrm{X} 9$ & 3.13 & 1.504 & 2.081 & 0.150 \\
\hline $\mathrm{X} 10$ & 2.161 & 1.527 & 1.415 & 0.235 \\
\hline
\end{tabular}

Source: own.

Table 6. Variance homogeneity test

\begin{tabular}{|l|c|c|c|c|}
\hline & Levene Statistic & gl1 & gl2 & Sig. \\
\hline Item1 & .007 & 1 & 304 & .936 \\
\hline Item2 & .477 & 1 & 304 & .491 \\
\hline Item3 & .041 & 1 & 304 & .840 \\
\hline Item4 & .978 & 1 & 304 & .324 \\
\hline Item5 & 2.402 & 1 & 304 & .122 \\
\hline Item6 & 1.042 & 1 & 304 & .308 \\
\hline Item7 & 2.800 & 1 & 304 & .095 \\
\hline Item8 & 3.061 & 1 & 304 & .081 \\
\hline Item9 & .084 & 1 & 304 & .773 \\
\hline Item10 & .507 & 1 & 304 & .477 \\
\hline
\end{tabular}

Source: own.

The ANOVA values are described in Table 5 on the mean squared of the inter groups and intra groups with degrees of freedom $\mathrm{gl}=1$ and $\mathrm{gl} 2=304$ respectively, as well as the values of the F statistic with its level of significance $>0.05$. These values provide evidence not to reject the hypothesis of equality of means, which leads us to think that there is no difference between the groups. In addition, the values described in Table 6 provide evidence so that the hypothesis of equality of variance is not rejected, so it is concluded that the populations of the two groups (men and women) are equal [20].

\section{Discussion}

From the main objective of the study that seeks to determine if engineering students have mobile phone addiction and if it differs with respect to gender, the following results are obtained: the mobile phone addiction test used designed by [19] showed 
reliability and acceptable internal consistency in the surveyed population $(\alpha=0.860)$. These psychometric properties had also been reported by [13] with a Cronbach's alpha of 0.91 , which allows us to affirm that the instrument has good theoretical validity.

Student participation was very balanced in relation to gender. The age range of the participants oscillates the highest percentage between 17 and 22 years $(82.03 \%$ ), of which between 17 and 19 represents $59.80 \%$ and between 20 and 22 the $22.22 \%$. These are the ages when this type of addiction-related phenomena can be observed the most and several studies on smartphone addiction have been conducted in the last decade in populations of university students, including: Korean students [1, 3 and 9], Thai [14], Lebanese [16], Italian [15], Turkish [5 and 8] and Saudi [10].

The factor analysis allowed the extraction of two components that group the ten items of the instrument used.

This finding differs from the one-dimensional model proposed by [19]. This result could be due to different circumstances, one of them related to the context in which the studies were developed, that of [19] in South Korea, and this one reported in the Mexican southeast.

It is important to highlight that although $38.2 \%$ (Table 4) showed medium levels of addiction and $40.8 \%$ low levels, they do not constitute sources of alarm, however, it is healthy to pay special attention in these cases, since prevention is a measure strategy that avoids reaching the next level, where the levels of addiction become of medical implications. All with the intention of ensuring that the conduct of telephone use does not affect their academic performance and their goal of successfully completing their professional engineering studies.

The results of the present research do not show significant evidence that there is a gender difference with respect to mobile phone addiction, neither as a result of the ANOVA tests nor with the Levene statistic to verify the homogeneity of the population variances. This finding contrasts with other studies that did discover significant gender differences, such as [25] who showed in their study that Spanish women between 12 and 18 years old had shown an excess in the use of mobile phones, compared to men. Similar to the study by [26], who show that the probability of greater use of the mobile phone was presented in women more than men. This also coincides with the work of [27], who identify worse consequences in women, precisely due to the abuse of the smartphone. These differences may come from the difference between age. In the [25] study participants were younger than in this research. Cultural features could be another explanation. According to [26] Asian female students tent to use more their smartphones than western female students.

\section{Conclusion}

Smartphone with its multifunctional features has gained significant importance as a must have gadget of study, work and everyday life [28]. Without a doubt, this feature can make students, and the user in general, see their life related or influenced by this device as a work or study tool. It is clear that the addiction to the telephone could in 
certain cases not be negative, as pointed out by [29], who states that in certain users the excessive time they use the mobile phone contributes to significantly reducing the possibility of acquiring another type of addiction, such as cigarettes or alcohol.

As [30] points out, the purpose of this article is not to advocate against the smartphone but indeed to inform the educational community so that to make informed decisions regarding the introduction of this kind of technology into the classroom. We can conclude that it is considered essential to carry out educational programs in order to promote the conscious use of the mobile phone and thus avoid a possible addiction. In addition, it is suggested to motivate students to be in movement through physical exercise. According to [31] the effect of physical activity is to significantly reduce the constant need to use the smartphone, because areas of the brain that are associated with the reward are stimulated, thereby improving the mood and maintaining a reflected inhibitory control in an acceptable performance and attention to the environment.

In a constructive self-criticism, the limitation that arose in the study was the conformation of the sample, since it was not probabilistic, it was determined considering the resources available at the time of carrying out the study, in addition to the facilities of the educational establishment to apply the survey. With this argument, it would be worth expanding the samples to other populations of informants in Latino contexts and preferably stratified samples for comparative studies.

In the same way, it is advisable to carry out some studies from the medical angle towards the possible implications of physical damage from addiction to the use of mobile phones, as reported by [32]. These authors pointed out that studies have already been carried out to investigate neurological and neuropsychological effects that could affect the cranial base, including intracranial tumors, all this, since the mobile phone works by emitting and receiving low-frequency electromagnetic waves.

Finally, it is suggested to carry out research to measure telephone harassment as has been done by [33] or the negative effect linked to sensory interference generated by excessive use, when driving the car, as studied by [34].

\section{$7 \quad$ References}

[1] Kim, D., Lee, Y., Lee, J., Nam, J.K. \& Chung, Y. (2014). Development of Korean smartphone addiction proneness scale for youth. PloS One, 9(5), e97920. https://doi.org/10.1371/ journal.pone.0097920

[2] Demirci, K., Orhan, H., Demirdas, A., Akpinar, A. \& Sert, H. (2014). Validity and reliability of the Tukish version of the Smartphone Addiction Scale in younger population. Bulletin of Clinical Psychopharmacology, 24(3), 226-34. https://doi.org/10.5455/bcp.20140710040824

[3] Choi, S.W., Kim, D.J., Choi, J.S., Ahn, H., Choi, E.J., Song, W.Y., Kim, S. \& Youn, H. (2015). Comparison of risk and protective factors associated with smartphone addiction and internet addiction. Journal of Behavioral Addictions, 4(4), 308-314. https://doi. org/10.1556/2006.4.2015.043 
[4] Kahyaoglu, S., H., Kurt, S., Uzal, O. \& Ozdilek, S. (2016). Effects of smartphone addiction level on social and educational life in health sciences students. Eurasian Journal of Family Medicine, 5(1), 13-9.

[5] Gökçearslan, Ş., Mumcu, F.K., Haşlaman, T. \& Çevik, Y.D. (2016). Modelling smartphone addiction: The role of smartphone usage, self-regulation, general self-efficacy and cyberloafing in university students. Computers in Human Behavior, 63, 639-649. https:// doi.org/10.1016/j.chb.2016.05.091

[6] Yehuda, L.B., Greenberg, L. \& Weinstein, A. (2016). Internet Addiction by Using the Smartphone-Relationships between Internet Addiction, Frequency of Smartphone Use and the State of Mind of Male and Female Students. Journal of Reward Deficiency Syndrome and Addiction Science, 2(1), 22-27. https://doi.org/10.17756/jrdsas.2016-024

[7] Arefin, S., Islam, R., Mustafi, M., Afrin, S. \& Islam, N. (2017). Impact of Smartphone addiction on academic performance of business students: a case study. Independent Journal of Management \& Production, 8(3), 955-975. https://doi.org/10.14807/ijmp.v8i3.629

[8] Darcin, A.E., Kose, S., Noyan, C.O., Nurmedov, S., Y1lmaz, O. \& Dilbaz, N. (2017). Smartphone addiction and its relationship with social anxiety and loneliness. Behaviour and Information Technology, 35(7), 520-525. https://doi.org/10.1080/0144929X.2016.1158319

[9] Lee, S., Kim, H.J., Choi, H.G. \& Yoo, Y.S. (2018). Smartphone Addiction and Interpersonal Competence of Nursing Students. Iranian Journal of Public Health, 47(3), 342-349.

[10] Alkhunzain, A. (2019). An Empirical Study on Smartphone Addiction of the University Students. International Journal of Interactive Mobile Technologies, 13(12), 184-195. https:// doi.org/10.3991/ijim.v13i12.11120

[11] Saad, M. (2020). Self-Regulated Learning and Academic Procrastination as Predictors of Smartphone Addiction among Second Year- Middle School Learning Disabled Students. Revista Amazonia Investiga, 9(26), 236-243. https://doi.org/10.34069/AI/2020.26.02.27

[12] Billieux, J., Maurage, P., Lopez-Fernandez, O., Kuss, D.J., \& Griffiths, M.D. (2015). Can disordered mobile phone use be considered a behavioral addiction? An update on current evidence and a comprehensive model for future research. Current Addiction Reports, 2, 156-162. https://doi.org/10.1007/s40429-015-0054-y

[13] López-Fernández, O. (2015). Short version of the smartphone addiction scale adapted to Spanish and French: Towards a cross-cultural research in problematic mobile phone use. Addictive Behaviors, 64, 275-280. https://doi.org/10.1016/j.addbeh.2015.11.013

[14] Penjira, K., Felicito, F., Ruangrit, R. \& Penjuree, K. (2016). An empirical study on the impact of self-regulation and compulsivity towards smartphone addiction of university students. 13th International Conference on Cognition and Exploratory Learning in Digital Age (CELDA 2016).

[15] Pavia, L., Cavani, P., Di Blasi, M. \& Giordano, C. (2016). Smartphone Addiction Inventory (SPAI): Psychometric properties and confirmatory factor analysis, Computers in Human Behavior, 63, 170-178. https://doi.org/10.1016/j.chb.2016.05.039

[16] Hawi, N. \& Samaha, M. (2016). To excel or not to excel: Strong evidence on the adverse effect of smartphone addiction on academic performance. Computers \& Education, 98, 81-89. https://doi.org/10.1016/j.compedu.2016.03.007

[17] Elhai, J.D., Levine, J.C., Dvorak, R.D. \& Hall, B.J. (2017). Non-social features of smartphone use are most related to depression, anxiety and problematic smartphone use. Computers in Human Behavior, 69, 75-82. https://doi.org/10.1016/j.chb.2016.12.023

[18] Cerit, B., Bilgin, N. \& Ak, B. (2018). Relationship between smartphone addiction of nursing department students and their communication skills. Contemporary Nurse, 54(4-5), 532-542, https://doi.org/10.1080/10376178.2018.1448291 
[19] Kwon, M., Kim D.J., Cho, H. \& Yang, S. (2013). The Smartphone Addiction Scale: Development and Validation of a Short Version for Adolescents. PLoS ONE 8(12): e83558. https:// doi.org/10.1371/journal.pone.0083558

[20] Hair, J., Anderson, R. \& Tatham, R. (1979). Multivariate Data Analysis: With Readings. Tulsa, Oklahoma: PPC Books. Prentice Hall PTR.

[21] Kline, R. (2005). Structural equation modeling. New York, United States: Guilford Press.

[22] Yela, M. (1966). Los tests y el análisis factorial. En B. Szekeli (Ed.), Los Tests (pp. 153-178). Buenos Aires: Kapelusz.

[23] Richaud, M. (2005). Desarrollos del análisis factorial para el estudio de ítem dicotómicos y ordinales. Revista Interdisciplinaria, 22(2), 237-251.

[24] Ogasawara, H. (2011). Asymptotic expansions of the distributions of the polyserial correlations coefficients. Behaviormetrika, 38, 153-168. https://doi.org/10.2333/bhmk.38.153

[25] Chóliz, M., Villanueva, V. \& Chóliz, M.C. (2009). Ellas, ellos y su móvil: Uso, abuso (¿y dependencia?) del teléfono móvil en la adolescencia. Revista Española de Drogodependencias, 34(1), 74-88. http://www.aesed.com/descargas/revistas/v34n1 6.pdf

[26] Takao, M., Takahashi, S. \& Kitamura, M. (2009). Addictive personality and problematic mobile phone use. CyberPsychology \& Behavior, 12(5), 501-507. https://doi.org/10.1089/ cpb.2009.0022

[27] Beranuy, M., Chamarro, A., Graner, C. \& Carbonell, X. (2009). Validación de dos escalas breves para evaluar la adicción a Internet y el abuso de móvil. Psicothema, 21(3), 480-485.

[28] Zahir, A. \& Omaid, M. (2020). The Use of Smartphones as an Educational Tool in the Classroom: Lecturers' Perceptions. International Journal of Emerging Technologies in Learning (iJIM), 15(16), 238-247. https://doi.org/10.3991/ijet.v15i16.14179

[29] Cassidy, S. (2006). Using social identity to explore the link between a decline in adolescent smoking and an increase in mobile phone use. Health Education, 106(3), 238-250. https:// doi.org/10.1108/09654280610658578

[30] Papadakis, St. (2020). Robots and Robotics Kits for Early Childhood and First School Age. International Journal of Interactive Mobile Technologies (iJIM), 14(18), 34-56. https://doi. org/10.3991/ijim.v14i18.16631

[31] Liu, S., Xiao, T., Yang, L. \& Loprinzi, P.D. (2019). Exercise as an alternative approach for treating smartphone addiction: a systematic review and meta-analysis of random controlled trials. International Journal of Environmental Research and Public Health, 16(20), 1-16. https://doi.org/10.3390/ijerph16203912

[32] Heinrich, S., Thomas, S., Heumann, C., Von Kries, R. \& Radon, K. (2011). The impact of exposure to radio frequency electromagnetic fields on chronic well-being in young people. A cross-sectional study based on personal dosimetry. Environment International, 37(1), 26-30. https://doi.org/10.1016/j.envint.2010.06.008

[33] Turan, N., Polat, O., Karapirli, M., Uysal, C. \& Turan, S.G. (2011). The new violence type of the era: Cyber bullying among university students: Violence among university students. Neurology, Psychiatry and Brain Research, 17(1), 21-26. https://doi.org/10.1016/j. npbr.2011.02.005

[34] Backer-Grøndahl, A. \& Sagberg, F. (2011). Driving and telephoning: Relative accident risk when using hand-held and hands-free mobile phones. Safety Science, 49(2), 324-330. https://doi.org/10.1016/j.ssci.2010.09.009 


\section{Appendix 1. English version of SAS-SV}

\begin{tabular}{|c|c|c|c|c|c|c|c|}
\hline \multicolumn{2}{|r|}{ Items } & Strongly & Disagree & $\begin{array}{l}\text { Weakly } \\
\text { Disaoree }\end{array}$ & Weakly & Agree & Strongly \\
\hline 1 & $\begin{array}{l}\text { Missing planned work due to } \\
\text { smartphone use }\end{array}$ & 1 & 2 & 3 & 4 & 5 & 6 \\
\hline 2 & $\begin{array}{l}\text { Having a hard time } \\
\text { concentrating in class, while } \\
\text { doing assignments, or while } \\
\text { working due to smartphone } \\
\text { use }\end{array}$ & 1 & 2 & 3 & 4 & 5 & 6 \\
\hline 3 & $\begin{array}{l}\text { Feeling pain in the wrists or } \\
\text { at the back of the neck while } \\
\text { using a smartphone }\end{array}$ & 1 & 2 & 3 & 4 & 5 & 6 \\
\hline 4 & $\begin{array}{l}\text { Won't be able to stand not } \\
\text { having a smartphone }\end{array}$ & 1 & 2 & 3 & 4 & 5 & 6 \\
\hline 5 & $\begin{array}{l}\text { Feeling impatient and fretful } \\
\text { when I am not holding my } \\
\text { smartphone }\end{array}$ & 1 & 2 & 3 & 4 & 5 & 6 \\
\hline 6 & $\begin{array}{l}\text { Having my smartphone in } \\
\text { my mind even when I am not } \\
\text { using it }\end{array}$ & 1 & 2 & 3 & 4 & 5 & 6 \\
\hline 7 & $\begin{array}{l}\text { I will never give up using my } \\
\text { smartphone even when my } \\
\text { daily life is already greatly } \\
\text { affected by it. }\end{array}$ & 1 & 2 & 3 & 4 & 5 & 6 \\
\hline 8 & $\begin{array}{l}\text { Constantly checking my } \\
\text { smartphone so as not to miss } \\
\text { conversations between other } \\
\text { people on Twitter or Facebook }\end{array}$ & 1 & 2 & 3 & 4 & 5 & 6 \\
\hline 9 & $\begin{array}{l}\text { Using my smartphone longer } \\
\text { than I had intended }\end{array}$ & 1 & 2 & 3 & 4 & 5 & 6 \\
\hline 10 & $\begin{array}{l}\text { The people around me tell me } \\
\text { that I use my smartphone too } \\
\text { much. }\end{array}$ & 1 & 2 & 3 & 4 & 5 & 6 \\
\hline
\end{tabular}

\section{Authors}

Arturo García-Santillán Researcher at National Technology of Mexico and Researcher \& Coordinator of doctoral program in Management Science at UCC Business School, Universidad Cristóbal Colón. Member of the National System of Researchers in Mexico. He has published more than two hundred papers in indexing journals, twenty books, and six chapter books. He has participated in almost 70 national and international congresses as a participant and speaker. He has Postdoctoral Studies in Applied Mathematics ESE-IPN, Ph.D. in Management Sciences (mayor) Financial (minor), MBA and Bachelor in Financial and Banking Management. Received an honorary doctorate degree from the World Knowledge Summit México 2020-2021 
and the "Colegio Internacional de Profesionistas C\&C". Also he obtained the Fischler Award in the USA for his research and publications on Financial Mathematics teaching, among others.

Elena Moreno-García Researcher Professor at Instituto Tecnológico Superior de Misantla and Universidad Cristóbal Colón in Mexico. She is highly ranked at the Mexican National Research System, level II. She obtained a PhD in Economics at Almeria University, Spain, a master degree in finance at Universidad de las AméricasPuebla and a Bachelor in Economics at Universidad Cristóbal Colón, Veracruz, Mexico. She has published more than forty papers about financial education and math anxiety in international indexed journals.

Valerie Martínez-Rodríguez is student at the Doctoral Program in Management Science at UCC Business School, Universidad Cristóbal Colón. She has a Master degree in Management and a Bachelor in Psychology at the Benemérita Universidad Autónoma de Puebla, Puebla.

Article submitted 2021-04-16. Resubmitted 2021-08-21. Final acceptance 2021-08-21. Final version published as submitted by the authors. 